\title{
Biofilm en Endodoncia: una revisión
}

\section{Biofilm in endodontics: a review}

\section{Resumen}

Están demostrados los esfuerzos que han hecho la Microbiología y la ciencia endodóntica para llegar a descifrar los secretos de esta singular estructura a pesar de que día tras día van surgiendo nuevos interrogantes. Necesitamos que los tratamientos que empleemos para combatir al biofilm logren oxigenar el ecosistema periapical y fundamentalmente raspar y desprender las bacterias fuertemente adheridas. Conociendo el proceso de formación del Biofilm, el metabolismo microbiano y las estrategias que ellos mismos utilizan para resistir y permanecer ocultos pero activos, sabremos por qué llegamos a observar lesiones periapicales refractarias.

Palabras claves: conducto radicular, Biofilm

\section{Abstract}

It is demonstrated the efforts made endodontic microbiology and science to get to decipher the secrets of this unique structure although every day new questions arise. We need the treatments we use to combat biofilm achieve oxygenate the periapical ecosystem and basically scrape and loosen the tightly adhering bacteria Knowing the process of biofilm formation, microbial metabolism and strategies that they use to resist and remain hidden but active, we know why we observe refractory periapical lesions. Key Words: Root canal ,biofilm

\section{Artículo de Revisión}

\section{Zambrano de la Peña Sonia, ${ }^{* 1}$ Salcedo-Moncada, Doris. ${ }^{2}$ Petkova- Gueorguieva, Marieta ${ }^{3}$ Ventocilla Huasupoma, María²}

1. Departamento Médico Quirúrgico de Odontología. UNMSM

2. Departamento de Estomatología Rehabilitadora de Odontología . UNMSM

3. Departamento de Ciencias Básicas de Odontología . UNMSM

Correspondencia:

Zambrano de la Peña Sonia

Correo electrónico:

facedent@hotmail.com

Facultad de Odontología de UNMSM, Jr. Amézaga 375, Lima 1, Perú.

Coautores

Salcedo- Moncada Doris endodoncista@hotmail.com

Petkova - Gueorguieva, Marieta mpgueorguieva@hotmail.com

Ventocilla Huasupoma, María

maria_ventocilla@hotmail.com

\section{Introducción}

La eliminación de los microorganismos de los conductos radiculares infectados ha sido y es una constante preocupación en endodoncia, demostrada por las investigaciones que evaluaron la eficacia de la instrumentación mecánica, la influencia de los irrigantes, la medicación intracanal y sistémica (Byström \& Sundqvist, 1981, 1983; Tronstad et. al., 1990). Actualmente el mejor y más seguro método utilizado para descontaminar el conducto es una limpieza profunda del contenido séptico-necrótico (Schilder, 1974),

En la cavidad bucal existen aproximadamente 1010 bacterias (Mims et al., 1995), con más de 700 diferentes especies de bacterias (Aas et al., 2005), los que buscan un nicho de nutrición; una de las funciones primarias del esmalte es proteger de esos microrganismos al complejo dentinopulpar. Cuando hay caries o trauma oclusal se abre un camino para la penetración bacteriana a través de los túbulos, todas las bacterias de la cavidad bucal tienen la oportunidad de invadir el espacio del conducto radicular, se ha identificado a un grupo en los conductos infectados (Kantz \& Henry, 1974; Wittgow \& Sabiston, 1975; Sundqvist 1994). Las interacciones entre los factores microbiológicos y la disponibilidad de nutrientes son los principales elementos que define la composición de la microbiota bucal (Sundqvist \& Figdor, 2003).

\section{Biofilm}

El Biofilm es una comunidad de organismos de una o varias especies embebidas en una matriz extracelular de polisacáridos unidos a una superficie sólida. Existen microorganismos que viven en el Biofilm y son 1000 veces más resistentes a los agentes antimicrobianos. ${ }^{1}$
Los nuevos conceptos de resistencia bacteriana en endodoncia están mostrando el importante papel del Enteroccocus Faecalis., los cuales fueron encontrados con mayor frecuencia al hacer el análisis de la microbiota de los conductos radiculares que presentaron infecciones persistentes. ${ }^{2}$ Una biopelícula es definida como una población microbiana adherida a un sustrato orgánico o inorgánico rodeada de productos extracelulares la cual forma una matriz intermicrobiana. ${ }^{3}$

Los microorganismos, organizados en biopelículas muestran una alta resistencia tanto a los agentes antimicrobianos como a los mecanismos de defensa del hospedero. Tronstad et al. en 1990 demostró la presencia de estas biopelículas en lesiones perirradiculares adyacentes al foramen apical y en colonias bacterianas dentro de granulomas periapicales. Los resultados de este estudio sugieren la posibilidad de que este mecanismo 
facilite la persistencia de la periodontitis apical crónica. Sin embargo, el porcentaje de biopelículas en lesiones perirradiculares de dientes no tratados endodónticamente es bastante bajo (4\%), por lo que constituyen un mínimo porcentaje de los casos fracasados. ${ }^{4}$

Costerton (1987) citado por SerranoGranger J. Y Herrera D. (2005) afirma que un Biofilm es la forma de crecimiento más frecuente de las bacterias y se definió en un principio como una comunidad de bacterias adheridas a una superficie sólida e inmersa en un medio líquido (Serrano-Granger J. y Herrera D. 2005). Donlan y Costerton (2002) citados por Gonçalves J. (2007) definen la biopelícula como una comunidad microbiana sésil e inmersa en un medio líquido, caracterizada por bacterias que están irreversiblemente adheridas a un sustrato, interface o las unas a las otras, permaneciendo embebidas en una matriz de polisacáridos extracelulares que ellas mismas producen, exhibiendo un fenotipo alterado con respecto a la tasa de crecimiento y la transcripción genética. Donlan continúa diciendo que cada comunidad microbiana en las biopelículas es única, aunque algunos atributos estructurales pueden ser generalmente considerados universales. ${ }^{5}$

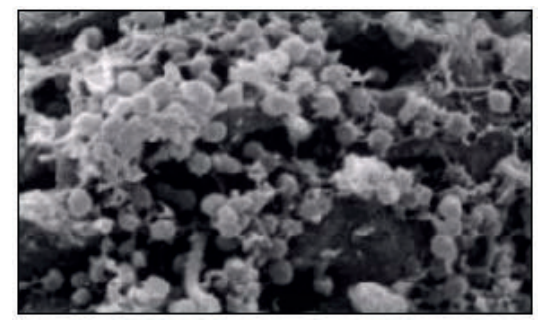

Microfotografía electrónica de barrido mostrando organizaciones bacterianas dentro de conductos radiculares infectados con lesiones perirradiculares. Colonias compuestas principalmente por cocos y bacilos escasos adheridos a la dentina. Algunas células invadiendo los túbulos dentinarios. 4000X. Tomado de Siqueira Jr. 2004.

Según la OMS, el Biofilm se puede definir también como un ecosistema bacteriano proliferante y enzimáticamente activo. Los biofilms se unen a superficies inertes, tanto biológicas como sintéticas. Dentro de las biológicas optan preferentemente por tejidos necróticos. $^{6}$

Chávez de Paz y col. opinan que el Biofilm no es raro ni infrecuente en el conducto necrótico sino que es la forma de vida bacteriana más habitual, y que es incorrecto pensar que son entidades excepcionales solo porque sea reciente su conocimiento y estudio en endodoncia. Dicha asociación puede ser entre bacterias de la misma o de distinta especie ${ }^{7}$.
La primera de ellas se denominada autoagregación y la segunda coagregación. La coagregación está considerada una forma de Biofilm más compleja y difícil de eliminar, ya que bacterias de distinta especie pueden compartir distintos mecanismos de defensa en pos del mantenimiento de la comunidad asociada en Biofilm. ${ }^{8,9}$

Para Siqueira y Rocas los casos de infección periapical crónica deben considerarse, al día de hoy, causadas por infecciones de tipo Biofilm. ${ }^{10}$

El Biofilm bacteriano apical es clínicamente importante porque los biofilms microbianos son inherentemente resistentes a los agentes antimicrobianos, no pueden ser removidos por la preparación biomecánica sola y podrían conducir a fracasos del tratamiento endodóntico como consecuencia de la infección persistente (Leonardo M. R. y col. 2002).

Las formas de Biofilm se han descrito muy variadas, desde pequeñas formaciones hasta cadenas de Biofilm, pero la formación más característica encontrada es la de Biofilm en forma de champiñón (mushroom-shape). Estas colonias se observan al microscopio como estructuras unitarias de la forma señalada, separadas de otras por canales de agua, todo dentro de la matriz de polisacárido. Se piensa que estos canales permiten la distribución de los nutrientes y la eliminación de los residuos de las colonias, así como la atenuación de los agentes biocidas externos, tales como antibióticos, irrigantes y medicaciones intraconducto. ${ }^{11,12}$

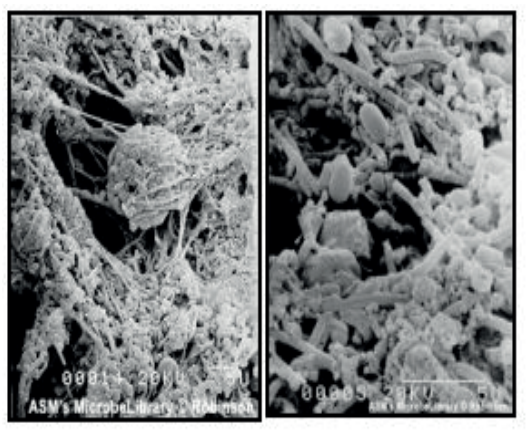

Microfotografías al Microscopio Electrónico de Barrido de biopelícula microbiana a diferentes magnificaciones. Tomado de http://www.microbelibrary.org/images/robinson/RROBSON7.jp

\section{Formacion del Biofilm}

El proceso de formación del Biofilm en el conducto radicular no es aún muy conocido. La teoría más aceptada consta de cuatro fases y fue descrita por Svensater y Bergenholtz. En la primera fase se forma una película adhesiva so- bre la dentina promovida por el depósito de proteínas y otros compuestos derivados de las bacterias en suspensión, del proceso necrosis y/o inflamación, etc. En la segunda fase, sobre esa película pegajosa, se fijan algunas bacterias especificas con capacidad de adhesión, de todas las que están en suspensión. En la tercera fase, la primera capa de bacterias ya adherida, segrega mediadores que, por un lado, van fijando más y más bacterias, de esa estirpe o de otras, y por otro, va formando la matriz extracelular de polisacárido, primera barrera defensiva característica del Biofilm. En la cuarta y última, el Biofilm va madurando y creando sistemas de defensa más complejos. Al mismo tiempo, arroja bacterias al exterior que cronifican la respuesta inflamatoria del huésped. Siqueira y Rocas exponen que en esta etapa el conjunto del Biofilm puede consistir en $15 \%$ de bacterias y $85 \%$ de matriz de polisacáridos, además de contar con más de 300 capas de bacterias superpuestas ${ }^{13}$

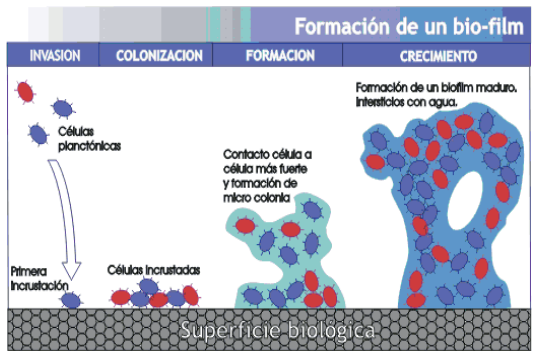

La figura ilustra el proceso de formación del biofilm: unión a la superficie, adherencia con otras células, formación de Microcolonias y maduración dentro de una capa de exopolisacarido. www.alientoassist.com/libro/book_2.htm. Microfotografía tomada de googleimages.com

Otra característica importante de la evolución del Biofilm es que puede aislarse del hábitat que le rodea si éste se vuelve exageradamente hostil y se han descrito formaciones en estado inerte en medios extremos. El Biofilm puede mantener dicho status por un tiempo, a la espera de que la situación del medio mejore, antes de perecer. Si el medio cambia a mejor, el Biofilm abandona el estado de latencia y sigue desarrollándose. Si el ambiente extremo se mantiene tiempo suficiente, puede hacer inviable la existencia del Biofilm. Por ello, los estudios enfocan el tratamiento hacia la eliminación directa o indirecta del Biofilm. ${ }^{14}$

\section{Mecanismo de Acción}

La característica fundamental, es una gran capacidad de resistencia. Esta capacidad se ve aún más aumentada en el interior del sistema de conductos ya 
que su anatomía proporciona zonas de difícil acceso a las soluciones irrigantes. La matriz de polisacáridos supone una barrera física y química, evitando así la penetración de agentes externos indeseables, cambios de $\mathrm{pH}$, etc., manteniendo un ambiente interior adecuado para la supervivencia y es considerado actualmente uno de los mecanismos más importantes. ${ }^{14}$

Un aspecto interesante es que este aislamiento del exterior pero con vías de comunicación interna fomenta el intercambio de material genético entre las bacterias que lo forman, favoreciendo la resistencia $y$, por tanto, aumentando la capacidad de defensa del Biofilm ${ }^{15}$.

Las enzimas producidas por el Biofilm, promueven la adhesión a otros sustratos o de otras bacterias y también actúan inactivando agentes químicos antiinfecciosos. El Biofilm puede ir desprendiendo bacterias sobrantes de su interior de forma paulatina para "distraer" la atención de los mecanismos de defensa del huésped, cronificando el proceso y ocasionando en el paciente picos de signos y/o síntomas puntuales que remiten tras la administración de antibióticos pero sin curar el "nido de origen". ${ }^{14}$

\section{Composición Bacteriana}

Los tipos bacterianos observados en el Biofilm de origen endodóntico son, fundamentalmente, cocos, bacilos $y$ filamentos, aunque ocasionalmente se han detectado espiroquetas. Las especies del género Prevotella son muy frecuentes debido a su capacidad de autoagregarse y coagregarse.

El Fusobacterium nucleatum es el componente central de muchos de los biofilms en infecciones odontogénicas, gracias a su enorme capacidad de coagregación y de resistencia a biocidas e incluso algunos consideran el F. nuclea- tum la bacteria clave o "puente" para el desarrollo del Biofilm. Ozok y col. encuentran sinergismo en la asociación en forma de Biofilm de Peptostreptococos micros y F. Nucleatum. Metzger y cols) comprobaron en varios estudios la importancia del F. nucleatum para iniciar biofilms y la afinidad con la Porphyromonas Gingivalis. Respecto al estudio del Enterococcus faecalis en relación al Biofilm, se ha postulado que la resistencia de esta bacteria a ser eliminada del interior del conducto, ya sea con instrumentación, irrigación y/o con medicación intraconducto, se debe a que puede asociarse en forma de Biofilm, George y cols. analizaron la ultraestructura del Biofilm de E. faecalis combinando medios ricos y pobres en nutrientes con medios aeróbicos y anaeróbicos en dientes extraídos. En sus resultados, exponen que el Biofilm más desarrollado en madurez y organizaciones el que se da en medio rico en nutrientes y anaeróbico, advirtiendo incluso las estructuras en forma de champiñón y canales de agua descritas por Distel y cols. En cambio, el medio rico en nutrientes y aeróbico formaba más cantidad de Biofilm pero de menor organización, aunque era el más proclive a invadir los túbulos dentinarios en profundidad. ${ }^{14}$

Llama la atención que los biofilms que crecen en medios pobres en nutrientes, aunque presentan un número de bacterias significativamente menor que los de medios ricos, aumentan la ratio calcio/ fósforo en suspensión y degradan más la dentina que les rodean, por lo que se cree que, en esas circunstancias de supervivencia compleja, estos biofilms tienden a calcificarse para aumentar sus defensas y ser aún más resistentes. ${ }^{16}$

Otra de las bacterias que se han descrito como formadoras de Biofilm en Endodoncia es el Streptococcus inter- medius. Se trata de una bacteria anaerobia facultativa Gram-positiva, como el E. Faecalis, Tarsi y col. opinan que es una de las más importantes en la formación de Biofilm, ya que descubrieron que tiene una gran capacidad adhesiva y postulan que incluso puede ser una de las especies primarias, generadoras de Biofilm. Además, se trata de una bacteria que se aísla comúnmente en infecciones endodónticas y presenta cierta resistencia a la remoción. ${ }^{14}$

\section{Biofilm Intrarradicular}

El Biofilm intrarradicular, está alojado en zonas de difícil acceso, mientras que las bacterias en suspensión se reparten por todo el sistema de conductos. Las zonas accesibles a las limas no necesitan de más ayuda para la eliminación de ambos tipos de presentación bacteriana, pero muchas zonas de este sistema no están al alcance de las limas, por lo que no pueden contactar con la infección y eliminarla. Nair y cols encontraron conductos en los cuales permanecían istmos inalterados por la preparación biomecánica, después de haber empleado tanto limas manuales como rotatorias, complementadas con irrigantes. En dichos istmos, no sólo persistía el Biofilm sino que la infección estaba asociada a tejido necrótico fibrodentinario. ${ }^{8} \mathrm{Se}$ argumenta que, de haber llegado los instrumentos, o al menos los irrigantes, dicho tejido debía haberse destruido y desaparecido, poniendo en peligro la evolución del Biofilm e, incluso, provocar su muerte por inanición. La respuesta del Biofilm al contacto con el irrigante es un enigma, y no se puede saber si hubiese sido disuelto, pero se deduce que el contacto entre irrigante e interior del istmo no se produjo por la presencia de ese tejido asociado. ${ }^{14}$
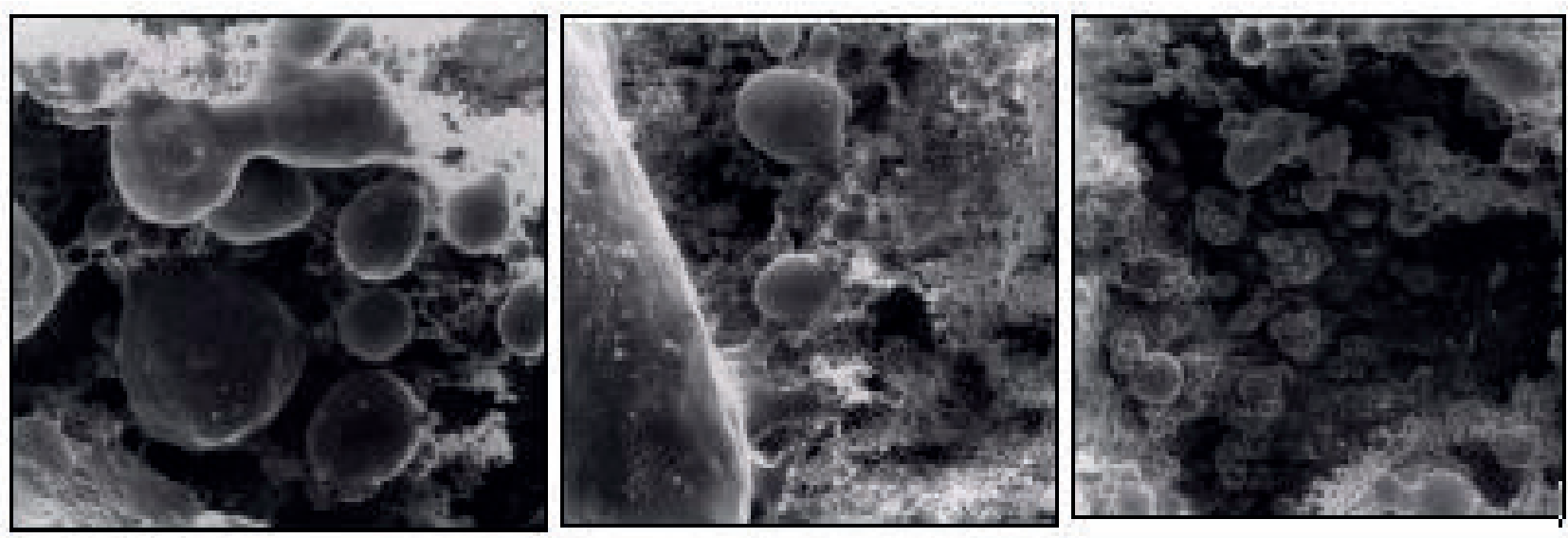

(a) Foramen lingual mostrando reproducción de levaduras. 1000X (b) levaduras adheridas a la gutapercha extruída del foramen lingual. 500X (c) cocos y levaduras. 1000X. Tomado de Ferreira, 2004 
El Biofilm tiene mayor capacidad de defensa que las bacterias en suspensión porque interacciona menos con el medio donde vive y depende menos de él, además de que su tasa de mitosis es mucho menor. Las bacterias asociadas en Biofilm no fomentan infecciones agudas, sino crónicas, debido al tipo de metabolismo del mismo y sus características. ${ }^{14}$

La persistencia del Enteroccocus Faecalis después del tratamiento del conducto radicular puede estar asociada con su capacidad para inducir reprecipitación de apatita en los biofilms maduros. La habilidad del Enteroccocus F. para formar un biofilm calcificado sobre la dentina de los conductos radiculares puede ser un factor que contribuya a su persistencia después del tratamiento endodóntico (Kishen A. y col.2006).

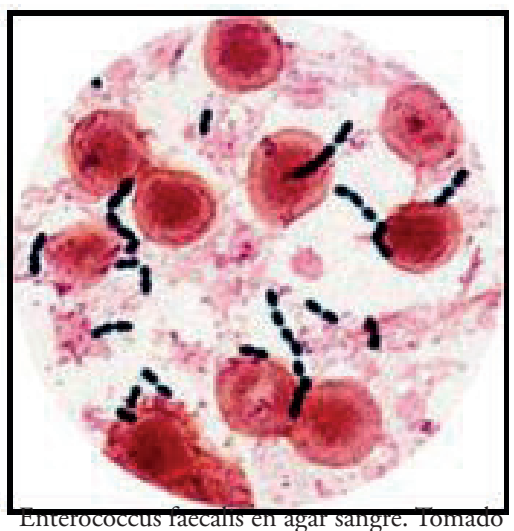

de www.genomenewsnetwork.org/.../ resistant. shtml

\section{Discusión}

En la mayoría de los dientes obturados con lesiones periapicales resistentes a la terapia, los microorganismos pueden persistir y jugar un rol significativo en los fracasos endodónticos (Nair P. N. R. y col. 1990). ${ }^{17}$

Los estudios mostraron una tasa de éxito de los dientes con periodontitis apical de 80 a $90 \%$, cuando el conducto radicular fue adecuadamente instrumentado, desinfectado y obturado. Esto significa que el 10 a $20 \%$ de las lesiones periapicales no responden al tratamiento local del diente. Lo que no se sabe es si la falta de respuesta de las lesiones periapicales refractarias es debido a la inaccesibilidad de los microorganismos extra radiculares o a la presencia de una microbiota que es diferente de aquella normalmente encontrada en las infecciones endodónticas (Titterud S. P. y col. 2002.) ${ }^{18}$

El agregado de hipoclorito de sodio activado ultrasónicamente por un minuto mejora significativamente los valores totales de limpieza de los conductos con instrumentación manual/rotatoria, son mejores que aquellos demostrados por otros autores utilizando el método de preparación step-back.

La formación de biofilms muestra ciertas características de supervivencia y virulencia bajo algunas situaciones (Duggan J. y col. 2007). ${ }^{19}$

Una completa remoción de tejido/biofilm/detritos provenientes de los istmos de los dientes es imposible con instrumentación manual o manual/rotatoria sola.

\section{Conclusiones}

1. El biofilm es un sistema biológico multifuncional interactivo donde cada microoganismo coopera con otros para formar una barrera que resista al sistema inmunológico como así también a los agentes antimicrobianos.

2. El biofilm puede localizarse dentro del sistema de conductos pudiéndose ocultar en diversas irregularidades anatómicas lo cual complicaría el tratamiento para erradicarlo, o también en la región periapical cuyo aporte nutritivo circulatorio, mucho más importante que el de la pulpa, les propiciará a los microorganismos una poderosa vía de difusión y diseminación para localizarse extrarradicularmente.

3. La necrosis pulpar crea un ambiente propicio para la proliferación microbiana debido a que los residuos y toxinas actúan como sustrato promoviendo condiciones selectivas para la formación de biofilms.

4. Una instrumentación adecuada acompañada por una irrigación abundante de $\mathrm{NaOCl}$ al $5.25 \%$ activada por ultrasonido y con un largo período de contacto entre solución /paredes del conducto y una medicación intraconducto es garantía de un pronóstico favorable.

5. El uso de una medicación antibacteriana entre citas ha sido lo más recomendado para eliminar las bacterias no afectadas por la preparación químico-mecánica (Siquiera J. F. y col. 2007).

\section{Referencias Bibliográficas}

1. Costerton J, Stewart P, Greenberg E. Bacterial biofilms: a common cause of persistent infections. Science. 1999 May 21;284(5418):1318-22.

2. Tronstad L, Barnett F, Cervone F. Periapical bacterial plaque in teeth refractory to endodontic treatment. Endod Dent Traumatol.

3. Viviani, M J. Patologia periapical. Estructura del Biofilm. Electronic journals of Endodontics Rosario. Año7.Vol 01. Abril 2008

4. Tronstad L, Barnett F, Cervone F. Periapical bacterial plaque in teeth refractory to endodontic treatment. Endod Dent Traumatol. 1990;6(2):73-7.

5. Costerton JW, Lewandowski Z, DeBeer D, Caldwell D, Korber D,James G. Biofilms, the customized microniche. J Bacteriol 1994; 176:2137-. 42.

6. Noiri Y, Ehara A, Kawahara T, Takemura N, Ebisu S. Participacion de biopelículas bacterianas en la periodontitis periapical refractaria y crónica. Endodoncia 2003;21(1):50-56.

7. Leonardo MR, Rossi MA, Silva LA, Ito IY, Bonifacio KC. EM evaluation of bacterial biofilm and microorganisms on the apical external root surface of human teeth. J Endod 2002;28:815-8

8. Chavez de Paz LE, Bergenholtz G, Dahlen G, Svensater G. Response to alkaline stress by root canal bacteria in biofilms. Int Endod J

9. $2007 ; 40: 344-55$

10. O’Toole G, Kaplan HB, Kolter R. Biofilm formation as microbial development.Annu Rev Microbiol 2000;54:49-79

11. Siqueira JF Jr, Rocas IN. Community as the unit of pathogenicity: an emerging concept as to the microbial pathogenesis of apical periodontitis.Oral Surg Oral Med Oral Pathol Oral Radiol Endod 2009; 107:870-8.

12. Ricucci D, Siqueira JF Jr, Bate AL, Pitt Ford TR. Histologic investigation of root canal-treated teeth with apical periodontitis: a retrospective study from twenty-four patients. J Endod 2009;35:493-502 
13. Siqueira J. Endodontic infections: concepts, paradigms, and perspectives. Oral Surg Oral Med Oral Pathol Oral Radiol Endod. 2002;94(3):281-93

14. Baumgartner J.C, Siqueira J.F, Sedgley C.M, Kishen A. Microbiology of endodontic disease in Ingle's Endodontics. Chapter 7. 6th ed. John I Ingle 2008:221-308.

15. F. Sirvent Encina, E. Garcia Barbero. Biofilm. Un nuevo concepto de infección en En-
dodoncia..Endodoncia - Volumen 28 • Numero 4 • OctubreDiciembre 2010

16. Saunders W, Saunders E. Coronal leakage as a cause of failure in rootcanal therapy: a review. Endod Dent Traumatol. 1994;10(3):105-8.

17. Clegg MS, Vertucci FJ, Walker C, Belanger M, Britto LR. The effect of exposure to irrigant solutions on apical dentine biofilms in vitro. J Endod 2006; 32:434-7.

18. Nair P, Sjogren U, Krey G, Kahnberg K, Sundqvist G. Intrara- dicular bacteria and fungi in rootfilled, asymptomatic human teeth with therapy-resistant periapical lesions: a long-term light and electron microscopic follow-up study. J Endod. 1990; 16(12): 580-8.

19. Tronstad L, Titterud P. The evolving new understanding of endodontic infections. Endodontic Topics 2003, 6, 57-77

20. Duggan J,Segdley C.Biofilm : formation of oral endodontics enterococcus Faecalis .J Endod 2007; 33(7): 815-818 